\title{
Strategy for Ecotourism Based on Intangible Heritage Local Wisdom
}

\author{
I Gusti Agung Ayu Gita Pritayanti Dinarm, I Nyoman Putu Budiartha \\ \{gitadinar@gmail.com\} \\ Faculty of Law, Warmadewa University
}

\begin{abstract}
Ecotourism plays an essential role in understanding, supporting and preserving the natural and rich cultural heritage of the Bali community. The character of Balinese culture and heritage which includes symbols, signs, written art expression, language, lifestyle, ritual systems, traditional knowledge and mythology inherited by their predecessors are the main attraction for the world of tourism. The changes and shifts in the way of life, culture, and ritual systems in society are inevitable due to the rapid global technological advancement. However, this shift is not a problem assuming the character and identity of Bali tends to always reflect their predecessors' cultural heritage. Tangible heritages are restored when there is damage due to natural selection, however, the reverse is the case in the preservation of intangible cultural heritage, which experiences changes because of the mixed use of various cultures in the world. Therefore, this study aims to determine the following (i) The philosophical study regarding the essence of preserving intangible cultural heritage and (ii) The concept of managing intangible cultural heritage of Bali for proper preservation with the dynamics of global cultural development. This is a qualitative research, with data validation developed through dialogue and special interviews by considering social phenomena in the community. Furthermore, data were collected through field observations and document studies, with the theory of space, human and culture correlation used to study the problem. This research has the ability to determine the essence of preservation and the concept of governance in Bali's intangible cultural heritage using the dynamics of global cultural development by comprehensively examining its objects, formation process and benefits to local, national and international communities. The result showed that a mutually supportive and decisive governance concept is needed to preserve and sustain the cultural system in Bali. Benchmarks for the preservation of cultural heritage are focused on the form and various surrounding factors in a deep, structured and systematic way.
\end{abstract}

Keywords : governance, preservation, intangible heritages.

\section{Pendahuluan}

Kearifan lokal tumbuh dan berkembang turun temurun dari para pendahulu masyarakat Bali yang sarat dengan filosofi kehidupan di Bali. Soebadio (1986) memberikan arti sebagai identitas atau kepribadian budaya bangsa. Kearifan lokal sebagai warisan budaya yang dialihkan dari generasi ke generasi penerusnya sebagai identitas suatu masyarakat tertentu. 
Bali adalah salah satu dari beberapa daerah di dunia yang memiliki daya tarik pada warisan budayanya sehingga mendatangkan jutaan wisatawan dari tahun ke tahun untuk melihat, mempelajari bahkan turut menerapkan budaya masyarakat Bali ini. Kehadiran para wisatawan asing dari seluruh penjuru dunia membawa serta budaya mereka yang turut mewarnai beberapa warisan budaya masyarakat Bali. Warna-warni warisan budaya yang berbaur dengan budaya asing cenderung dianggap lebih nyaman untuk dilakukan oleh masyarakat sekitar komunitas ini, karena beberapa faktor diantaranya yaitu bahasa dan gaya hidup yang terlihat berbeda dengan warisan budaya sendiri, cenderung lebih modern dan bermanfaat untuk mempermudah masyarakat lokal Bali berinteraksi dengan wisatawan asing lainnya yang memiliki konsep budaya serupa. Jika percampuran budaya ini semakin diminati untuk diterapkan oleh generasi berikutnya maka ikatan identitas generasi pendahulunya akan semakin pudar dan seiring perjalanan waktu akan terlupakan.

Permasalahan dari pergeseran perilaku dan ketidak tertarikan generasi baru dengan warisan budaya menjadi masalah yang terlihat sederhana namun sangat mendasar. Diperlukan suatu konsep tata kelola warisan budaya yang bisa mencakup lebih banyak unsur-unsur pendukung pelestarian warisan budaya tidak berwujud (intangible heritages).

Penelitian ini secara umum bertujuan untuk mengembangkan Ilmu Hukum terkait dengan paradigma science as a process (ilmu sebagai proses), dengan paradigma ini ilmu tidak akan pernah mandeg (final) dalam penggaliannya atas kebenaran. Dalam penelitian ini adalah penggalian atas kebenaran dari strategi pengembangan ekowisata berbasis kearifan lokal intangible heritages.

\section{Metode Penelitian}

Penelitian ini menggunakan metode penelitian kualitatif, dengan mengembangkan validasi data melalui dialog, wawancara khusus dengan memperhatikan fenomena sosial di masyarakat, dengan peneliti sebagai instrumen pokok. Teknik pengumpulan data yang relevan dalam penelitian ini yaitu dengan cara: (i) pengamatan (observasi lapangan) dan (ii) studi dokumen. Interaksi dialektikal antara peneliti dan responden untuk menginterpretasi, membandingkan, merkonstruksi realitas yang diteliti melalui metode-metode kualitatif seperti participant observation. Adapun pendekatan yang digunakan dalam penelitian ini yaitu pendekatan Analisa Konsep (Analitical and Conceptual Approach) yaitu segala permasalahan ditelaah berdasarkan konsep, teori, asas-asas, dan peraturan perundang-undangan yang berlaku. Penelitian ini menggunakan data sekunder sebagai data awal kemudian dilanjutkan dengan data primer yang didapat melalui studi lapangan.

\section{Hasil Dan Pembahasan}

\subsection{Kajian filosofis mengenai hakikat pelestarian warisan budaya intangible.}

Ilmu yang terus berkembang dan mencari kebenaran memiliki karakteristik atau ciri khas, yakni selalu bertumpu pada tiga tiang penyangga perkembangan ilmu, yaitu ontologis, epistimologis dan aksiologis. Ontologis bicara tentang apa realitas yang ada dalam alam semesta, epistemologis bicara tentang bagaimana metodelogi, validasi dan kesahihan sebuah pengetahuan dan aksiologis bicara tentang nilai dan tujuan. Sebuah penelitian yang dikaji 
berdasarkan unsur filosofis sepatutnyalah memenuhi syarat tiga tiang penyangga ilmu tersebut, sehingga diharapkan hasilnya dapat memberikan nilai-nilai yang bermanfaat dan dapat diuji kebenarannya. Ontologi membahas tentang apa yang ingin kita ketahui, seberapa jauh kita ingin tahu, atau dengan perkataan lain suatu pengkajian mengenai teori tentang "ada". Obyek dari penelitian ini adalah warisan budaya intangible, metode pengembangan dari ekowisata merupakan suatu proses validasi pengetahuan sehingga pengetahuan ini akan memberikan manfaat nantinya di masyarakat.

Van Peursen mendefinisikan budaya dengan teori korelasi, ruang (alam), manusia dan kebudayaan termasuk proses perubahan yang terjadi di alam ruang alam itu, baik sebagai akibat reaksi manusia terhadap alam maupun akibat dari perilaku alam dan manusia. Jauh sebelumnya masyarakat Bali telah menerima warisan kearifan (filosofi) tentang kesejahteraan yang paripurna yang berakar pada konsep Tri Hita Karana, yaitu konsep keseimbangan antara manusia dengan manusia, manusia dengan Tuhannya dan manusia dengan alam. Konsep asal usul budaya ini saling terkait antara manusia, alam dan kebudayaan. Budaya manusia diwariskan dari kelompok manusia sebelumnya kepada kelompok manusia generasi selanjutnya sebagai identitas, jati diri dan mencirikan keberadaan masyarakat Bali.

Lestari berarti tetap seperti keadaan semula, tidak berubah, bertahan dan kekal. Pentingnya pelestarian warisan budaya sebagai upaya dalam menjaga ikatan identitas dari generasi yang lampau dengan yang sekarang. Melestarikan keserasian dan keseimbangan lingkungan berarti membuat tetap tak berubah atau kekal keserasian dan keseimbangan lingkungan. Keserasian adalah suatu hal yang relatif dan subyektif. Warisan budaya tidak berwujud (intangible) sebagai obyek dalam penelitian ini didefinisikan sebagai: The preservation of the cultural heritage now covers the non-physical cultural heritage, which includes the signs and symbol passed on by oral transmission, artistic and literary forms of expression, languages, ways of life, myths, beliefs and rituals, value system and traditional knowledge and know-how.

Warisan budaya Bali sangat didukung pelestariannya oleh konsep ecotourism atau ekowisata yang didefinisikan oleh The Ecotourism Society tahun 1996 sebagai kegiatan perjalanan wisata yang bertanggung jawab di daerah yang masih alami atau daerah-daerah yang dikelola dengan kaidah alam dimana tujuannya selain untuk menikmati keindahan juga melibatkan unsur pendidikan, pemahaman dan dukungan terhadap usaha-usaha konservasi alam dan peningkatan pendapatan masyarakat setempat sekitar daerah tujuan ekowisata. Konsep ekowisata idealnya akan menjaga keutuhan dari warisan budaya intangible sehingga akan dapat diwariskan dari generasi ke generasi selanjutnya mencegah pudarnya indentitas masyarakat Bali. Hakikat dari pelestarian budaya intangible heritages yakni menjaga keseimbangan dan keserasian hasil pikiran, akal budi, adat istiadat yang telah berkembang termasuk didalamnya tanda, simbol, yang diturunkan secara lisan, kesenian, bahasa, cara hidup, mitologi, kepercayaan, sistem ritual dan sistem nilai dan pengetahuan tradisional untuk mengerjakan sesuatu.

3.2 Konsep tata kelola terhadap warisan budaya intangable Bali sehingga dapat dilestarikan dengan dinamika perkembangan budaya global.

Konsep adalah ide atau pengertian yang diabstrakkan dari peristiwa konkret. Obyek pikiran harus bersifat nyata atau berbentuk fakta. Konsep pelestarian budaya Bali merupakan kegiatan yang mengakui, menghormati dan menghargai hak-hak sejarah dan hak-hak kultural masyarakat.Konsep pelestarian budaya sesungguhnya sudah diatur dalam Pasal 2 Peraturan Menteri Pendidikan dan Kebudayaan Republik Indonesia Nomor 81A Tahun 2013 tentang Implementasi Kurikulum, yakni: 
Implementasi kurikulum pada SD/MI, SMP/MTs, SMA/MA, dan SMK/MAK menggunakan pedoman implementasi kurikulum yang mencakup:

a. Pedoman Penyusunan dan Pengelolaan Kurikulum Tingkat Satuan Pendidikan;

b. Pedoman Pengembangan Muatan Lokal;

c. Pedoman Kegiatan Ekstrakurikuler;

d. Pedoman Umum Pembelajaran; dan

e. Pedoman Evaluasi Kurikulum.

Konsep tata kelola warisan budaya intangible harus dimulai sejak sangat dini pada generasi baru yakni:

1. Memperdalam pengetahuan masyarakat terhadap hakikat dan fungsi suatu warisan budaya intangible melalui media cetak, sosial media dan menggiatkan dharma wecana secara rutin dan konsisten di setiap daerah.

2. Menerapkan kurikulum muatan lokal tentang budaya Bali yang beragam seprti bahasa daerah Bali, tarian Bali, gamelan, kuliner Bali, mitologi, pada Sekolah-sekolah Dasar internasional yang kini sangat popular di kalangan masyarakat menengah ke atas.

3. Mengaktifkan kembali kegiatan-kegiatan pendukung kesenian (tarian tradisional Bali, gamelan dan aktivitas kesenian Bali lainnya) dan sistem ritual di Puri-Puri, Jero dan menghidupkan kembali kegiatan sanggar tari di daerah-daerah ekowisata.

4. Melakukan kerja sama secara rutin dengan asosiasi industri pariwisata Bali seperti Gabungan Industri Pariwisata Indonesia (GIPI) Bali beserta segenap stakeholder terkait untuk memberikan sosialisasi mengenai pentingnya ekowisata berbasis kearifan lokal khususnya pada warisan budaya intangible ke Sekolah-sekolah Dasar internasional yang berada di Bali.

Berdasarkan wawancara peneliti secara informal dengan beberapa Elementary International School (Sekolah Dasar) di Bali, muatan lokal yang diajarkan pada siswa masih belum maksimal dan konsisten yakni:

1. Terdapat tipe Sekolah Dasar Internasional yang tidak memasukkan program muatan lokal budaya Bali pada mata pelajaran kesenian ataupun dalam program ekstrakurikuler;

2. Terdapat tipe Sekolah Dasar Internasional yang hanya menjadwalkan muatan lokal berupa tarian kesenian Bali dan gamelan hanya pada saat hari perayaan tertentu;

3. Terdapat tipe Sekolah Dasar Internasional yang sudah menerapkan beberapa jenis muatan lokal budaya Bali dalam program belajar mengajar dengan jenis muatan lokal yang berbeda setiap semester ajaran. 


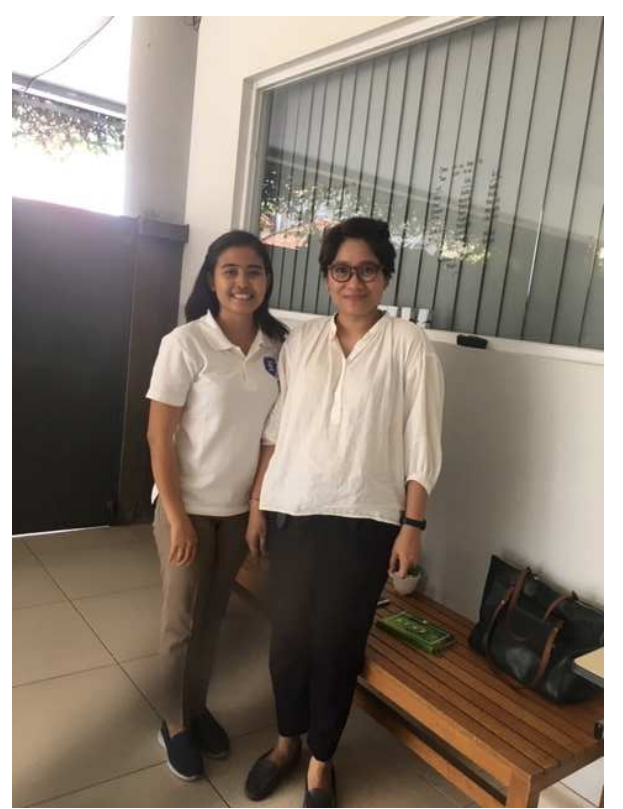

Wawancara peneliti secara informal dengan salah satu guru, Ibu Yuni sebagai Student Coordinator pada Regents School Bali.

Meskipun muatan lokal telah diatur dalam Peraturan Menteri Pendidikan dan Kebudayaan namun belum terdapat keseragaman dan komitmen pelaksanaannya pada beberapa Sekolah Dasar Internasional di Bali mengenai pelestarian warisan budaya intangible melalui kurikulum muatan lokal sehingga hasil yang di dapat belum akan maksimal sesuai harapan pendahulu masyarakat Bali. Jika jumlah Sekolah Dasar Internasional dengan tipe yang sama sekali tidak mencantumkan program muatan lokal pada proses ajar mengajar meningkat, maka warisan budaya Bali khususnya intangible akan segera pudar mengingat bahwa ketertarikan masyarakat menengah untuk mendaftarkan anak-anaknya pada Sekolah Dasar Internasional meningkat tajam bahkan tidak sedikit yang masuk dalam daftar tunggu dalam beberapa tahun untuk dapat terdaftar menjadi siswa Sekolah Dasar Internasional.

\section{Kesimpulan}

Hakikat dari pelestarian budaya intangible heritages yakni menjaga keseimbangan dan keserasian hasil pikiran, akal budi, adat istiadat yang telah berkembang termasuk didalamnya tanda, simbol, yang diturunkan secara lisan, kesenian, bahasa, cara hidup, mitologi, kepercayaan, sistem ritual dan sistem nilai dan pengetahuan tradisional untuk mengerjakan sesuatu. Konsep tata kelola warisan budaya intangible berdasarkan fakta yang ada di masyarakat: meningkatkan pengetahuan masyarakat sejak dini terhadap wawasan warisan budaya intangible, seperti bahasa daerah, kesenian, kuliner, mitologi, gamelan Bali dan mengaktifkan kembali kegiatan sanggar tari baik di Puri, Jero dan daerah-daerah ekowisata, bekerjasama dengan industri pariwisata untuk melakukan sosialisasi mengenai pentingnya ekowisata berbasis kearifan lokal dengan konsisten khususnya pada Sekolah Dasar Internasional di Bali. 


\section{References}

[1] Dasi Astawa I Nengah, Gede Sedana, 2017, Kearifan Lokal Bali dan Pembangunan Ekonomi, Pustaka Larasan, Denpasar.

[2] Derita Prapti Rahayu, 2014, Budaya Hukum Pancasila, Thafa Media, Yogyakarta.

[3] Jujun S. Suriasumantri, 2015, Ilmu Dalam Perspektif, Yayasan Pustaka Obor Indonesia, Jakarta.

[4] Otto Soemarwato, 1994, Ekologi Lingkungan Hidup dan Pembangunan, Djambatan, Jakarta.

[5] Sukma Arida Nyoman, 2015, Dinamika Ekowisata Tri Ning Tri di Bali, Fakultas Pariwisata Universitas Udayana, Denpasar.

[6] Supasti Dharmawan, 2011, Hak Kekayaan Intelektual dan Harmonisasi Hukum Global Rekonstruksi Pemikiran Terhadap Perlindungan Program Komputer, Universitas Diponegoro, Semarang.

[7] Wyasa Putra, Ida Bagus, 2013, Filsafat Ilmu: Filsafat Ilmu Hukum, Udayana University Press, Denpasar.

[8] Wyasa Putra, Ida Bagus, 2017, Landasan Teoritik: Pengaturan Pelestarian Warisan Budaya Bali Sebagai Suatu Model, Udayana University Press, Denpasar.

[9] Departemen Pendidikan Nasional, 2016, Kamus Besar Bahasa Indonesia Pusat Bahasa Edisi Keempat, Gramedia, Jakarta. 